\title{
THE PATTERN OF LUNG FUNCTION ABNORMALITIES IN SMOKERS OF GINNING MILL WORKERS
}

\author{
Dr. Sujatha Talikoti. ${ }^{1}$ Dr Anand N Patil. ${ }^{2}$ Dr. Manjunatha Aithala. ${ }^{3}$ Dr. Sumangla Patil. ${ }^{4}$ \\ 1. Assistant Professor, Department of physiology BLDE University Sri BM Patil Medical College And Research Center \\ BIJAPUR -586103; KARNATAKA. \\ 2. Associate Professor, Department of Medicine AL-AMEEN Medical College BIJAPUR \\ 3. Professor and HOD, Department of physiology BLDE University Sri BM Patil Medical College And Research Center \\ BIJAPUR -586103; KARNATAKA. \\ 4. Professor, Department of physiology BLDE University Sri BM Patil Medical College And Research Center \\ BIJAPUR-586103; KARNATAKA.
}

Background: The cotton mill workers have increased prevalence of both obstructive and restrictive lung functions compared with control studies. Smoking was found to be an important risk factor for byssinosis and duration of exposure to cotton dust has also been reported to associated with chronic bronchitis, cough, dyspnoea ,evaluate the relation between smoking and incidence of byssinosis in ginning mill workers.

Aims and objectives: To determine chronic effects of long term exposure to cotton dust and to Respiratory symptoms in study group-200 ginning(cotton) mill workers. It is further divided into GROUP-I [130] Workers who exposed directly to the cotton dust. GROUP-II [70] Who are not directly exposed but working in other areas like office, watchman etc. Control group- [70] Non-Teaching staff members from BLDEU's Shri BM Patil Medical College, from the same socioeconomic group were taken. The various lung functions like FEV1[ml], FVC[ml], FEV1\% and PEFR[lit/min] were measured by using Bendict's recording spirometry and asking questionnaires. GROUP-I [50] and GROUP-II [25] smokers were identified.

Statistical analysis was done by 'Z' test and ANOVA test was applied to calculate mean values in various groups.

Results: We found [50] smokers in GROUP-I [130] and [25 ]from GROUP-II [70] .All the lung function parameters were significantly decreased in smokers when compared with non-smokers and controls. where $\mathrm{P}$ value is $[\mathrm{P}<0.05]$

Conclusion: The smokers are more prone to respiratory disorders and byssinosis compared to non-smokers who are working in ginning mill factory. The lung function parameters were also decreased in the smokers compared to non-smokers group.

Keywords; Byssinosis, Pulmonary function tests, Smoking

\section{INTRODUCTION}

The Cotton mill workers have increased prevalence of both obstructive and restrictive lung functions compared with control studies. Smoking was found to be an important risk factors for

byssinosis and duration of exposure to cotton dust has also been reported to be associated with chronic bronchitis, cough, dyspnoea. ${ }^{1}$

Byssinosis also called Brown Lung or Brown Lung disease is a type of Pneumoconiosis caused by dust from cotton and other fibers. Inhaled dust stimulates histamine release which causes constriction of the air passages, making breathing difficult over time.The dust accumulates in the lung producing a typical discolourisation that gives the disease its common name.

The disease afflicts mill workers and it takes several years of exposure before manifestations are noticed. ${ }^{2}$ Epidemiologic studies of cotton mill workers have demonstrated evidence of chronic lung disease resulting from occupational exposure to cotton dust. ${ }^{3}$

Initially workers have chest tightness and shortness As of breath on the first day of work week. These symptoms subsides as the week continues. the disease progresses, symptoms worsen and may persist through the work week as well as in the absence of work exposure. ${ }^{4,5}$

We have characterized the pattern of lung function abnormalities in cotton mill workers and may be both obstructive and restrictive. ${ }^{6}$ In smokers the lung function parameters are decreased compare to non smokers of working population. 
Cotton mill workers have an increased prevalence of both obstructive and restrictive lung function patterns compared with control subjects. Similar abnormal patterns are observed with respiratory disease of other etiologies, notably these associated with smoking.

\section{MATERIALS AND METHODS}

To determine chronic effects of long term exposure to cotton dust and to evaluate the relation between smoking and incidence of byssinosis in Ginning(cotton) factory mill workers.

\section{Study group-200 ginning mill male workers.}

Control group- [70] Male Non-Teaching staff members from BLDEU's Shri BM Patil Medical College , from the same socioeconomic group were taken.

GROUP-I [130] Workers who exposed workers directly to the cotton dust.

GROUP-II [70] Who are not directly exposed to the cotton dust but working in other areas like office work, watchmen etc. The various lung functions like FEV1[ml], FVC[ml], FEV1\% and PEFR[lit/min] [best of 3 readings] were measured by using Bendict's recording spirometry and asking questionnaires designed by Muralidhar, et .al in their study .Same questionnaire was used by Parikh and National Institute of occupational ,Health, Ahmedabad ${ }^{7,8}$ [NIOSH, 1994]. From GROUP-I [50] and From GROUP-II [25] smokers were identified. Total $\{n=75\}$ smokers were grouped as Study group. Statistical analysis was done by ' $Z$ ' test and ANOVA test was applied to calculate mean values in various groups.

\section{Methods of collection of data;}

At the beginning the smokers and non smokers are identified and differentitated and the purpose of the study and content of the consent form was explained to them.

\section{Exclusion criteria;}

Subjects with history of tuberculosis, bronchial asthma, and deformities like gross Kyphosis.

\section{RESULTS}

Table I ; Relationship between Smoking and incidence of Respiratory Symptoms In Group I and Group II subjects. No. of subjects with respiratory symptoms

\begin{tabular}{|l|l|l|}
\hline Workers Group & Smokers & Nonsmokers \\
\hline $\begin{array}{l}\text { Group-I } \\
\text { No-130 }\end{array}$ & 50 & - \\
\hline $\begin{array}{l}\text { Group-II } \\
\text { No-70 }\end{array}$ & 25 & - \\
\hline
\end{tabular}


Table II: Different pulmonary function parameters in various categories of Smokers and nonsmokers. values are in \pm SD

\begin{tabular}{|c|c|c|c|c|}
\hline & & \multicolumn{3}{|c|}{ Group of Subjects } \\
\hline Parameters & Smoking habits & Controls & Group-I & Group-II \\
\hline \multirow{2}{*}{ FVC(ml) } & Smokers & - & $1728.81 \pm 320.4 \mathrm{NS}$ & $2007.23+543.63 *$ \\
\hline & Non-smokers & $2399.5+588.614$ & $1731.25 \pm 179.15$ & $2890 \pm 625.89$ \\
\hline \multirow[t]{2}{*}{ FEV1(ml) } & Smokers & - & 1148.30 $\pm 314.99 *$ & $1705.26+663.81 *$ \\
\hline & Nonsmokers & $2117 \pm 565.38$ & 1368.75+109.89 & $2820 \pm 570.74$ \\
\hline \multirow[t]{2}{*}{ FEV1\% } & Smokers & - & $65.45 \pm 9.92 *$ & $77.31 \pm 12.23 *$ \\
\hline & Nonsmokers & $88.3 \pm 0.104$ & $79.08+6.055$ & $97.80+3.12$ \\
\hline \multirow[t]{2}{*}{$\operatorname{PEFR}(\mathrm{L} / \mathrm{min})$} & Smokers & - & $220.6 \overline{7}+55.58 \mathrm{NS}$ & $327.10 \pm 37.04 *$ \\
\hline & Non smokers & $400.6 \pm 101.58$ & $238.75 \pm 47.64$ & $354 \pm 61.88$ \\
\hline
\end{tabular}

\section{NS-Not significant, ${ }^{*}$-Significant $\mathbf{P}<\mathbf{0 . 0 5}$.}

We found that [50] smokers in GROUP-I [130] and [25] from GROUP-II [70] .All the lung function parameters are[ FVC, FEV1[ml], FEV1\% and PEFR L/min] significantly decreased in smokers when compared with non-smokers and control workers . where $\mathbf{P}$ value is $[\mathbf{P}<0.05]$.

The smokers are more prone to respiratory disorders and byssinosis compared to non-smokers of cotton mill workers. The lung function parameters were also decreased in the smokers compared to non-smokers group.

\section{DISCUSSION:}

Evidences provided by various researchers suggests that byssinosis and other respiratory symptoms are more prevalent among smokers. ${ }^{9,10}$

In our study we have observed that all the workers suffering from one or other type of respiratory disorders are smokers. None of the non-smoker worker suffered from any type of respiratory disorders.

Among men the byssinotic index increased with smoking and dust exposure. Byssinotic workers were found have more chronic bronchitis and dyspnoea than matched controlled workers, It is influenced by cotton dust exposure and smoking. ${ }^{11}$

\section{CONCLUSION}

The smokers are more prone to respiratory disorders and byssinosis compared to non-smokers. The lung function parameters were also decreased in the smokers compared to non-smokers group. Byssinosis is influenced by cotton dust exposure and smoking.

\section{BIBLIOGRAPHY:}

1. http;//chestjournal.chestpubs.org/content/95/5/997

2. www.stat.uiowa.edu/....gwoodwor/..../Logistic-Analysis.Byssinosis.pdf.

3. Beck CJ.Schachter EN.The evidence for chronic lung disease in cotton textile workers,Ann stat 1983,$37 ; 404-12$.

4. Bouhuys A.Wolison RL,Horner DW,Brain JD,Byssinosis in cotton workersANN Intern med.1989,71;257-89.

5. Schilling RSF.Byssinosis in cotton and other textile workers Lancer 1956,2;261-65.

6. SchachterEN,MaunderI.R,Beck,CJ,t he pattern of lung abnormalities in cotton textinile 
7. Murlidhar V,Murlidhar VJ.Kahere V.'Byssinosis ina Bombay textile mill'.Natl Med J India;1995Sep-Oct;8[5];204-7.

8. JR Parikh,L J Bhagia,P K Majumdar,A R Shah,and S K ashyap. Prevalence of byssinosis in textile mills at Ahmedabad,India. Br J Ind Med.Nov-1989; 46[11];787-790.

9. FOX AJ. TOMBLESON JBL,et al, 1973.'A survey of respiratory disease in cotton operation Part I" Symptoms and ventilation test results.Br.J Ind Med;42-7.

10. KHOGALI M. 1976- "Byssinosis; a follow up study of cotton ginnery workers in sudan".Br J Ind Med;33;166-74.

11. Byssinosis and Chronic Bronchitis Among Cotton Textile worker. James A. Merchant, M.D.; Kaye H , et al. Annals of Internal medicine March 1,1972 vol-76 